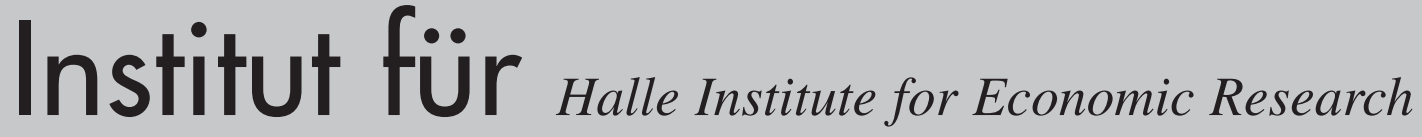 Wirtschaffsforschung Halle
}

Systematic Mispricing in European Equity Prices?

Marian Berneburg, MSc Economics

\section{IWH-Diskussionspapiere IWH-Discussion Papers}




\title{
Systematic Mispricing in European Equity Prices?
}

\author{
Marian Berneburg, MSc Economics
}


Author: Marian Berneburg, MSc Economics

Halle Institute for Economic Research

Department of Macroeconomics

Tel.: ++49/(0)345 7753812

Fax: $++49 /(0) 3457753820$

Email: marian.berneburg@iwh-halle.de

The responsibility for discussion papers lies solely with the individual authors. The views expressed herein do not necessarily represent those of the IWH. The papers represent preliminary work and are circulated to encourage discussion with the author. Citation of the discussion papers should account for their provisional character; a revised version may be available directly from the author.

Suggestions and critical comments on the papers are welcome.

IWH-Discussion Papers are indexed in RePEc-Econpapers.

Herausgeber:

INSTITUT FÜR WIRTSCHAFTSFORSCHUNG HALLE (IWH)

Prof. Dr. Ulrich Blum (Präsident), Dr. Hubert Gabrisch (Forschungsdirektor)

Das IWH ist Mitglied der Leibniz-Gemeinschaft

Hausanschrift: Postfach 1103 61, 06017 Halle (Saale)

Postanschrift: Kleine Märkerstraße 8, 06108 Halle (Saale)

Telefon: +49345775360

Telefax: +49345775320

Internet: http://www.iwh-halle.de 


\title{
Systematic Mispricing in European Equity Prices?
}

\begin{abstract}
One empirical argument that has been around for some time and that clearly contradicts equity market efficiency is that market prices seem too volatile to be optimal estimates of the present value of future discounted cash flows. Based on this, it is deduced that systematic pricing errors occur in equity markets which hence cannot be efficient in the Efficient Market Hypothesis sense. The paper tries to show that this so-called "excess volatility" is to a large extend the result of the underlying assumptions, which are being employed to estimate the present value of cash flows. Using monthly data for three investment style indices from an integrated European equity market, all usual assumptions are dropped. This is achieved by employing the Gordon Growth Model and using an estimation process for the dividend growth rate that was suggested by Barsky and DeLong. In extension to Barsky and DeLong, the discount rate is not assumed at some arbitrary level, but it is estimated from the data. In this manner, the empirical results do not rely on the prerequisites of stationary dividends, constant dividend growth rates as well as non-variable discount rates. It is shown that indeed volatility declines considerably, but is not eliminated. Furthermore, it can be seen that the resulting discount factors for the three investment style indices cannot be considered equal, which, on a risk-adjusted basis, indicates performance differences in the investment strategies and hence stands in contradiction to an efficient market. Finally, the estimated discount rates underwent a plausibility check, by comparing their general movement to a market based interest rate. Besides the most recent data, the estimated discount rates match the movements of market interest rates fairly well.
\end{abstract}

Keywords: Equity Market Efficiency; Discounted Cashflow; Excess Volatility; Variance Bound Test, Rational Expectations

JEL-Codes: G12; G14 


\section{Zusammenfassung}

Ein empirisches Argument besagt, dass Aktienpreise zu volatil sind, um optimale Schätzer des Barwerts zukünftiger Dividendenerträge zu sein. Auf Basis dieser Aussage wird gefolgert, dass systematische Schätzfehler an Aktienmärkten exitistieren, die eine Effizienz im Sinne der Hypothese Effizienter Märkte ausschließen. Das Paper versucht zu zeigen, dass diese so genannte "exzessive Volatilität" zu einem Großteil auf restriktive Annahmen zurückzuführen ist, die für die Schätzung des "korrekten" Barwerts der zukünftigen Erträge herangezogen werden. Basierend auf monatlichen Daten dreier Indizes, die verschiedene Investmentstrategien wiederspiegeln und einem integrierten europäischen Gesamtmarkt entstammen, wird auf alle üblichen Annahmen verzichtet. Dies wird mit Hilfe des Gordon Growth Models erreicht. Die Wachstumsraten der Dividenden werden mit einem Ansatz von Barsky und DeLong geschätzt. Als Erweiterung zu Barsky und DeLong werden allerdings die Diskontraten aus den bestehenden Daten approximiert. Es zeigt sich, dass in der Tat der Volatilitätsüberschuss der Marktpreise drastisch gesenkt wird. Allerdings verschwindet er nicht gänzlich, sondern bewegt sich grundsätzlich auf ähnlichem Niveau wie in einer früheren Studie des Autors, in der nur die Annahme, dass Dividenden einem stationären Prozess folgen, gelockert wurde. Ein weiteres Ergebnis des Paper ist, dass die geschätzen Diskontfaktoren der drei Investmentstrategien statistisch gesehen unterscheidlich sind, was für sich genommen darauf hindeutet, dass die Marktteilnehmer die risikoadjustierten Erträge dieser Strategien unterschiedlich einschätzen. Abschließend wurden die geschätzten Diskontraten einem Plausiblitätstest unterzogen. Es zeigte sich, dass abgesehen vom aktuellen Rand die geschätzten Diskontraten ein ähnliches Verhalten an den Tag legen wie ein marktbasierter Zinssatz.

Schlagwörter: Aktienmarkteffizienz; Discouned Cashflow; Excess Volatility; Variance Bound Tests; Rationale Erwartungen

JEL-Codes: G12; G14 


\section{Systematic Mispricing in European Equity Prices?}

\section{Contents}

Contents

1 Introduction $\quad 6$

$\begin{array}{llr}2 & \text { Theoretical background and methods } & 8\end{array}$

2.1 Shiller's original approach and some criticisms . . . . . . . . . 8

2.2 A Model without Shiller's assumptions . . . . . . . . . . . . . . . . . 10

2.3 Data . . . . . . . . . . . . . . . . . . . . 14

$\begin{array}{llr}3 & \text { Results } & 19\end{array}$

4 Conclusion $\quad 25$

$\begin{array}{ll}\text { References } & 27\end{array}$ 


\section{Introduction}

The question how efficient financial markets really are is a long way from being answered and has far reaching implications. A large degree of inefficiency could in fact put the very existence of the financial markets in danger, as they would cease to fulfill their objectives: Efficient allocation of resources, risk diversification, and aggregation of financial information. On the other hand, if a small degree of inefficiency should exist, it would open the opportunity for supra-normal profits, which of course would be in the interest of many practitioners. ${ }^{1}$ Up to the late 1970 s, efficiency, as defined by Fama's (1965) efficient market hypothesis (EMH), was generally accepted among practitioners as and academics. But since the early/mid-1980s the idea of inefficient and psychological pricing based on the theories of behavioral finance has gained an ever increasing group of followers.

The following paper takes a look at the question of equity market efficiency by analyzing whether prices are too volatile to qualify as efficient estimates of a fundamental price.

The paper uses Shiller's (1981) finding of excess volatility as a starting point. Applying a simple and very intuitive approach, which since has become widely used (e.g. Berneburg (2006), Heaney (2004), Cuthbertson and Hyde (2002), Kleidon (1986b)), Shiller showed that prices seemed too volatile to be an efficient estimate of the sum of discounted cash flows/dividends, which led him to reject the efficient market hypothesis. While it is easy to replicate Shiller's findings and arrive at the same conclusions, one has to rely on some fairly restrictive assumptions. Earlier studies only relaxed some of Shiller's assumptions (Berneburg (2006), and Barsky and DeLong (1993), for example), while this paper discards all assumptions: allowing for a non-stationary dividend process, variable discount and non-constant dividend growth rates. This is achieved by employing a slightly adapted version of the Gordon Growth Model (GGM) (Gordon, 1962). In doing so, the study shows that Shiller's excess volatility findings are to a large extent the result of his restrictive assumptions.

Usually, articles researching excess volatility in equity markets use data from the US or other major national financial markets, but an integrated European market, which is focus of the paper at hand, so far has not been a research subject. In the past decades, and not just since the introduction of the Euro, European financial markets have increasingly integrated and such phenomena as "home market bias" (Levy and Sarnat, 1970, for example) actually have declined considerably or possibly even diminished (Hardouvelis, Malliaropulos and Priestley, 2006). The increased competition among the European exchanges and their attempts to concentrate their industry is just one among an array of indications for this process of integration.

$\overline{1}$ In fact, a strand of financial market researchers even believe that some small degree of inefficiency is needed, in order to provide market participants with the incentive to collect information (Kyle, 1985, for example). 
In other words, it seems increasingly necessary to treat European financial markets as a single unified entity rather than just several separate national units. It is this reason why the paper at hand focuses on pan-European indices, which only in the past few years have become available in a sufficient length to support the necessary methods.

Besides the geographic focus, special attention is given to the major LargeCap investment/equity styles, i.e. a broad Standard (market normal), a Value and a Growth index. Equity styles, which group shares according to some characteristic (e.g. in the case of Value investment low price-earnings ratios is one possible characteristic), are an ideal research subject when analyzing market efficiency, as the philosophy, which they are based upon, inherently assumes inefficient markets as to allow supernatural, risk-adjusted average returns. ${ }^{2}$

$2 \quad$ For a detailed introduction to style investment, refer to "The Handbook of Equity Style Management" (Coggin, Fabozzi and Arnott, 1997). 


\section{Theoretical background and methods}

After a brief introduction to Shiller's (1981) approach and some of the criticism concerning his results, the paper will discuss the extensions of this paper as well as the used data.

\subsection{Shiller's original approach and some criticisms}

Shiller's (1981) claim of excess volatility in equity prices is based on a simple approach. According to the higher forms of the efficient market hypothesis (semi-strong and strong) (Fama, 1965) the current price of a share $\left(P_{t}\right)$ is an optimal estimate of the share's innate or correct or fundamental value $\left(P_{t}^{*}\right)$ :

$$
P_{t}=E_{t}\left(P_{t}^{*}\right)
$$

Or, to put it differently:

$$
P_{t}^{*}=P_{t}+u_{t}
$$

so that the market price $\left(P_{t}\right)$ plus some white noise error with zero mean $\left(u_{t}\right)$ equals the correct or fundamental value $\left(P_{t}^{*}\right)$, which is equal to the present value of expected future cash flows. ${ }^{3}$

$$
P_{t}^{*}=\sum_{k=0}^{\infty} \gamma^{k+1} E_{t}\left(D_{t+k}\right)
$$

where $\gamma=\frac{1}{1+r}$ is a constant discount factor, with $(0<\gamma<1)$, $r$ is the required return for one period, i.e. discount rate (risk-free rate plus a risk compensation),

$3 \quad$ Dividend payments do not represent all possible cash flow payments, but since data about other forms of cash flows, such as windfall profits in the case of mergers or share repurchases, is difficult to obtain, dividend payments are usually used to approximate all cash flows. The reasoning behind this approach is that in the long-run all increases in value will have to result in some form of dividend payment of which share repurchases are just a special case. But it should be clear that especially in a limited time frame and when looking at shares of relatively new companies, such as in the Growth segment, it could very well be that one is not capturing the appropriate measures. These new companies today tend to refrain from paying dividends, as they assume possible profits are more lucratively invested in their own growing firm rather than letting investors take the money to the financial markets. As a result, using only dividends as a measure to determine a "true" value, would not lead to appropriate results. So in other words, especially the Growth segment has the potential to be undervalued in this study. 
$E_{t}$ is mathematical expectation,

$D_{t+k}$ is dividends k-periods into the future.

Based on this set-up, Shiller (1981) performs a simple variance decomposition:

$$
\begin{aligned}
\operatorname{var}\left(P_{t}^{*}\right) & =\operatorname{var}\left(P_{t}+u_{t}\right) \\
\Leftrightarrow \operatorname{var}\left(P_{t}^{*}\right) & =\operatorname{var}\left(P_{t}\right)+\operatorname{var}\left(u_{t}\right)+2 \cdot \operatorname{cov}\left(P_{t}, u_{t}\right)
\end{aligned}
$$

Since $P_{t}$ is considered an optimal estimate of $P_{t}^{*}, P_{t}$ and $u_{t}$ should be independent such that $\operatorname{cov}(P, u)=0$.

$$
\Rightarrow \operatorname{var}\left(P_{t}^{*}\right)=\operatorname{var}\left(P_{t}\right)+\operatorname{var}\left(u_{t}\right)
$$

given $\operatorname{var}\left(u_{t}\right) \geq 0$

$$
\begin{aligned}
& \Rightarrow \operatorname{var}\left(P_{t}^{*}\right) \geq \operatorname{var}\left(P_{t}\right) \\
& \Leftrightarrow \sigma^{2}\left(P_{t}^{*}\right) \geq \sigma^{2}\left(P_{t}\right)
\end{aligned}
$$

or

$$
\sigma\left(P_{t}^{*}\right) \geq \sigma\left(P_{t}\right)
$$

To put it verbally, the standard deviation of market prices $\left(P_{t}\right)$ should be smaller or at most equal to the standard deviation of the present value of future dividend payments. ${ }^{4}$ If this was not to hold, systematic mispricing would take place in the market, which obviously cannot be an efficient situation. ${ }^{5}$

In his classic article, Shiller (1981) quite strongly falsifies market efficiency on the basis of this approach. According to his results, the ratio of the standard deviations of $P$ and $P^{*}$, which, if the EMH was to hold, should at most be equal to one, as it is implied by inequality (9), was 5.6 and 13.8 for the S\&P 500 and the Dow Jones Industrial Average, respectively.

At this point, it should be mentioned that Shiller's results are based on three central assumptions:

1. prices and dividends have a constant growth rate over time,

$4 \quad$ At this point, it should be mentioned that the use of variances and standard deviations implicitly assumes that either $P_{t}^{*}$ and $P_{t}$ are stationary or that they follow a common trend, i.e. that they are cointegrated. Otherwise the use of volatility measures such as variances and standard deviations would be meaningless, since they would depend on the observed data frequency as well as the time window in focus.

5 It should be noted that inequalities (8) and (9) cannot be calculated as such as not all states at time $t$ are known. The process process variance/standard deviations are being used as approximations: $\operatorname{var}\left(P^{*}\right) \geq \operatorname{var}(P)$ and $\sigma\left(P^{*}\right) \geq \sigma(P)$. 
2. dividends follow a variance stationary process,

3. the discount rate is constant over time.

Naturally, these assumptions attracted most of the criticism concerning Shiller's findings.

For example, Kleidon (1986a; 1986b) showed that Shiller's results are sensitive to the underlying dividend process. He assumed dividends to follow a random walk ${ }^{6}$ and was able to substantially reduce the findings of excess volatility. Similarly, Berneburg (2006) using data for an unified European stock market and based on a simple static GGM, hence assuming a random walk with drift in dividends, but relying on constant expected dividend growth as well as discount rates and factors, showed that a long-run relationship (i.e. cointegration) between prices and dividends can be observed. The long-run relationship between prices and dividends indicated that prices reacted about twice as strong to changes in dividends than it should be the case if the EMH were to hold. Furthermore, Barsky and DeLong (1993), footing their analysis on an adjusted Gordon Growth Model (GGM) (Gordon, 1962) and assuming a complex non-stationary dividend process, were able to show that excess volatility can be accounted for by variations in the dividend growth rate. Going hand in hand with Barsky and DeLong (1993), ${ }^{7}$ the use of constant discount rates was questioned by Kleidon (1988), Gillies and LeRoy (1991), Campbell (1991), Cochrane (1992), Cuthbertson and Hyde (2002) and even Shiller (1981) himself. While Shiller (2003) comes to the conclusion that variable discount rates alone cannot explain the large variations in share prices, Campbell (1991) and Cochrane (1992) argue that changing discount rates account for the largest part of equity price fluctuations. The unifying message of the literature seems to be that Shiller's assumptions essentially a priori reduce volatility in the fundamental price substantially. The question that hence arises is whether excess volatility diminishes when all assumptions are relaxed, in fact, whether excess volatility is simply the result of Shiller's assumptions.

\section{$2.2 \quad$ A Model without Shiller's assumptions}

It is this question about Shiller's assumptions that is central to this paper. A previous study, also using European equity style data (Berneburg, 2006), showed

$6 \quad$ Besides the empirical evidence (Kleidon, 1986b), there are good reasons to assume that dividends follow a random walk. Since the weak form market efficiency seems to hold (e.g. Berneburg (2004), Coggin (1998), Chow, Pan and Sakano (1996) and Lo (1991)), prices should follow a random walk. Furthermore, if one assumes a long-run relationship between prices and dividends (e.g. Berneburg (2006) and Heaney (2004)), dividends themselves should follow a random walk.

$7 \quad$ In the Gordon model, the discount factor results from the dividend growth rate $(g)$ as well as the required rate of return $(r)$. In other words, letting the growth rate of dividends change over time (i.e. $g_{t}$ ) will essentially make the whole discount factor flexible. 
three main results. Firstly, when using the same set-up as Shiller, the impression of excess volatility is also given for an unified European market. Secondly, relaxing the assumption of stationary dividends led to a substantial if not complete reduction in excess volatility. Thirdly an analysis on the basis of the static Gordon Growth Model (Gordon, 1962)(i.e. both the growth rate of dividends $(g)$ and the required rate of return $(r)$ were assumed to be constant) revealed a long-run relationship between prices and dividends. A multivariate cointegration analysis resulted in one cointegrating vector between prices and dividends and showed that the long-term elasticity of prices with respect to dividends was roughly two, whereas it should be one if the present value model were to hold. In other words, this analysis also led to the conclusion that prices are too responsive to changes in dividends, but to a much smaller extent than in Shiller's findings. The reason why excess volatility did not diminish completely was seen in the fact that the study only relaxed one of Shiller's assumptions and the growth rates for dividends as well as the discount rate still were assumed to be constant. It was hypothesized that if they were to fluctuate, the volatility of the fundamental price would increase substantially and with it excess volatility of market prices would decrease.

In detail, the paper at hand uses the following set-up while relaxing all of Shiller's original assumptions. Similarly to Berneburg (2006), the classic Gordon Growth Model (GGM) (Gordon, 1962) is the basis for the analysis. Since the GGM usually uses constant rather than variable values for dividend growth and discount rates the following modification is needed. For annual data it takes the following form:

$$
P_{\tau}^{* a}=\frac{1+g_{\tau}}{r_{\tau}-g_{\tau}} D_{\tau}^{a}
$$

When using monthly data, as is the case in this analysis, the GGM is changed once more:

$$
\Leftrightarrow \ln \left(P_{t}^{*}\right)=\ln \left(\frac{1+g_{t}}{r_{t}-g_{t}}\right)+\ln \left(\sum_{i=0}^{11} D_{t-i}\right)
$$

with $\ln \left(P_{t}^{*}\right)=p_{t}^{*}$ and $\ln \left(\sum_{i=0}^{11} D_{t-i}\right)=d_{t}^{r s}$

$$
p_{t}^{*}=\ln \left(\frac{1+g_{t}}{r_{t}-g_{t}}\right)+d_{t}^{r s}
$$

According to equation (12) the fundamental log-price $\left(p_{t}^{*}\right)$ is a log-linear function of the variable discount factor $\left(\ln \left(\frac{1+g_{t}}{r_{t}-g_{t}}\right)\right)$ and the $\log$ of twelve month rolling sums of dividends $\left(d_{t}^{r s}\right) .{ }^{8}$ Together with the implicit assumption of the GGM that dividends

$8 \quad$ The model in equation (12) corresponds to the rolling sums model in Berneburg (2006), which uses monthly data and a rolling sum of the past twelve months of dividend payments (refer to 2.3$)$. 
follow a random walk, the time dependency of the discount factor represents the relaxation of all of Shiller's assumptions. Because the growth rates for dividends $\left(g_{t}\right)$ (assumption number one) and the discount rates $\left(r_{t}\right)$ (assumption number three) are variable, the discount factor $\left(\ln \left(\frac{1+g_{t}}{r_{t}-g_{t}}\right)\right)$ is non-constant as well. ${ }^{9}$

Given data on prices and dividends, this version of the GGM requires values for $g_{t}$ and $r_{t}$. While this slightly modified GGM uses variable dividend growth and discount rates, it implicitly assumes that there are some constants $g$ and $r$, which are unknown to market participants. ${ }^{10}$ The values of $g$ and $r$ constantly have to be re-estimated such that one receives the time series $g_{t}$ and $r_{t}$. The estimation process for $g_{t}$ was suggested by Barsky and DeLong (1993) building on work by Muth (1960) and follows a simple intuition. Since market participants don't know the constant growth rate of dividends $(g)$, they use past data to arrive at an estimate: the average of all past dividend growth rates provides a good option. But in order to take account of structural changes in the form of transitory shocks that are possibly taking place and which cannot be ruled out, current information is also being considered. Keeping this in mind the estimation procedure takes the following form:

$$
g_{t}=(1-\theta) \sum_{i=0}^{t} \theta^{i} \Delta d_{t-i}^{r s}+\theta^{t}(\bar{g})
$$

with $\theta \in[0 ; 1], t=\{0, \ldots T\}$ and $\bar{g}=\frac{1}{T+1} \sum_{i=0}^{T} \Delta d_{i}^{r s}$

In detail, the estimation process in equation (13) implies that market participants obtain values for $g_{t}$, their estimate of the permanent dividend growth rate, on the basis of two parts: first, the average of all dividend growth rate $\left(\bar{g}=\frac{1}{T+1} \sum_{i=0}^{T} \Delta d_{i}^{r s}\right)$ corresponds to a permanent component and second, a distributive lag model with exponentially declining weights of dividend growth rates, $\sum_{i=0}^{t} \theta^{i} \Delta d_{t-i}^{r s}$ which represents transitory effects to the growth rate. The smaller $\theta$, the greater the effect of the transitory element. ${ }^{11}$ In other words, although market participants assume a permanent growth rate for dividends, ex ante they do not dismiss the idea of shifts in it, which would be in line with long-run changes in productivity and profitability. An example of a situation when such an approach seemed plausible was the late 1990s. In the beginning of the so-called "New Economy", it was unclear whether the technological advances in the telecommunications sector would lead to a jump in productivity or a permanent increase in the growth rate of productivity. In the latter case, a change in the expected future earnings and hence future cash flows

$9 \quad$ Assumption number one requires the growth rate of dividends and prices to be constant. The reason why Shiller (1981) assumes a constant growth rate in prices is because he detrends them. This step is not taken here, so that there is no need to consider this part of assumption number one.

10 This assumption is needed as otherwise the GGM would not be an appropriate representation of the infinitely long present discounted cash flow model as shown above in equation (12).

The special case of $\theta=0$ and $i=0$ (i.e. $0^{0}$ ) is defined as equal to one. 
from equity shares would have been the consequence. So, rather than just relying on an average of all past growth rates as the value for $g$, most recent changes are being considered as well, in order to be able to account for them if they turn out to have a permanent effect on the growth rate of dividends. ${ }^{12}$ This allows to quickly account for possible permanent effects as soon as they might occur.

While this estimation procedure reminds of a classic case of adaptive expectations, in this specific case it corresponds to rational expectations of market participants. Muth (1960) shows that it is ex ante optimal to use a distributive lag model with exponentially declining weights, if one wants to forecast a random walk with transitory white noise errors. Just as Barsky and DeLong (1993), this paper explicitly assumes such a process. ${ }^{13}$

Arriving at values for the discount rate $\left(r_{t}\right)$ is slightly more difficult. The discount rate consists of the market participants' time preferences as well as a risk premium. While the time preferences are determined individually by each investor, the risk premium depends on the specific asset. So if one would be able to match the equity shares under consideration and a market traded corporate bonds in terms of their risk level, the corresponding interest rate would be a natural choice for $r_{t}$. The market mechanism would serve as an aggregation tool for the different time preferences. But the case at hand does not allow for this approach. The used equity style indices correspond to different levels of risk and hence require different values for the discount rate. It is unclear, though, what the right matching bond would be, as one cannot completely be certain of the correct risk premium. Alternatively, one can use the data for prices and dividends to calculate past values of $r_{t}$ and see which estimation procedure can be assumed to be used by market participants.

Given the values for $g_{t}$ (the estimate of the dividend growth rate), this analysis proceeds by using two different ways to estimate the discount rate $\left(r_{t}\right)$ resulting in two alternative fundamental values of $p_{t}$. The first approach follows Barsky and DeLong (1993) in the sense that despite the model's formulation (equation (12)) $r_{t}$ is set at a constant $r$. But, in contrast to Barsky and DeLong (1993), the value for $r$ is not chosen arbitrarily (in Barsky and DeLong (1993) it was 6\% p.a.), the analysis at hand uses the estimate of $g_{t}$, the data for $d_{t}$ and substitutes $p_{t}$ for $p_{t}^{*}$ to solve equation (12) for $r_{t}$. This gives the discount rate $\left(r_{t}^{c}\right)$ needed to perfectly match market prices to the fundamental price as resulting from the GGM:

12 It should be noted that in the original version of equation (13) Barsky and DeLong (1993) use $g_{0}$ instead of $\bar{g}=\frac{1}{T+1} \sum_{i=0}^{T} g_{i}$, with $T+1$ observations, as the estimate of the permanent component. Unfortunately, due to the starting date of the used data, which falls into the $1970 \mathrm{~s}, g_{0}$ is negative in case of the used Standard and Value index. While this seems plausible temporarily, it surely is not appropriate when it represents the permanent component of the estimation procedure. In an ex post analysis, it seems a good alternative to use the sample mean as the permanent component.

13 This assumption allows for temporary deviations, i.e. transitory shocks, from the constant long-run behavior. Even if this was not to hold, the transitory effect would be excluded from the estimation through the size of the weighting factor $(\theta)$, so that the assumption in this case would be inconsequential. 


$$
r_{t}^{c}=\left(\frac{1+g_{t}}{e^{p_{t}-d_{t}}}\right)
$$

The constant value for the discount rate $(r)$ then is set at the sample mean of this calculated optimal discount rate $\left(\overline{r^{c}}=\frac{1}{T+1} \sum_{t=0}^{T} r_{t}^{c}\right)$ such that the fundamental value of $p_{t}$ under these assumptions $\left(p_{t}^{c}\right)$ is calculated as follows:

$$
p_{t}^{c}=\ln \left(\frac{1+g_{t}}{\overline{r^{c}}-g_{t}}\right)+d_{t}
$$

The second approach treats $r_{t}$ in the same way as $g_{t}$ was handled before. It is assumed that market participants estimate $r_{t}$ using the same procedure and same value for $\theta$ as in equation (13). While the subjective time preference should be known to each market participant the estimation of the risk premium leaves an opportunity for market participants to learn from market outcomes, i.e. discount rates in the past. This suggests an estimation procedure, which is based on the same intuition as equation (13):

$$
\begin{aligned}
r_{t}^{v} & =(1-\theta) \sum_{i=0}^{t} \theta^{i} \Delta p_{t-i}+\theta^{t}(\bar{r}) \\
& \Rightarrow p_{t}^{v}=\ln \left(\frac{1+g_{t}}{r_{t}^{v}-g_{t}}\right)+d_{t}
\end{aligned}
$$

The results for equations (15) and (17), the two alternative fundamental values of $p_{t}$, are then being implemented in Shiller's standard deviation bound (left hand side of inequality (9)) in order to analyze whether excess volatility can be observed. Furthermore, the estimated series $r_{t}^{c}$ will be compared with an alternative market based and representative interest rate to judge its feasibility. While this comparison does not allow to judge whether risk premia are estimated correctly, the levels of risk of the used interest rate and the equity style indices are most likely not the same, it gives an insight into the appropriateness of the estimated time preferences. Finally, the differences in the discount factors between the observed investment strategies (Standard, Value and Growth) will be analyzed, in order to draw some conclusions about the effectiveness of the equity styles.

\subsection{Data}

The analysis uses monthly data from MSCI-Barra (2005), who provide a large array of international indices and which are a standard tool of analysis in financial market. 
The used indices cover the EU15 $5^{14}$ plus Switzerland, which geographically as well as in terms of time span was the best match for a pan-European unified share market at the time of conducting this study. Three different indices are being used: a broad Standard LargeCap (Standard), as well as a Value and a Growth index, which are both based on the Standard index..$^{15}$ The Standard index consists of about 600 shares, while Value and Growth are comprised of nearly 250 and 400 stocks, respectively. The data starts in December 1969 for the Standard, and in December 1974 for the Value and Growth indices. It ends for all indices in July 2005. In order to arrive at more economically meaningful values, all index values were corrected for inflation by deflating them with the implicit GDP deflator for EU-12, ${ }^{16}$ which was obtained from the OECD (2005). ${ }^{17} 18$ Each time series is available as price and total return index. While the former is simply an index of prices, the latter considers dividend payments, by reinvesting them in the index ${ }^{19}$ MSCI-Barra calculates the total return index as follows:

$$
P F_{t}=P F_{t-1} \cdot\left(\frac{D_{t}+P_{t}}{P_{t-1}}\right)
$$

where

14 The EU15 consists of Germany, France, Italy, Spain, Portugal, Greece, Netherlands, Belgium, Luxembourg, Ireland, Austria, Finland, Great Britain, Sweden, Denmark.

15 Value and Growth are specific equity style investment strategies which group shares according to specific characteristics. An example for Value are shares with low price-earnings ratios. Growth equity, on the other hand, tends to be stock with constant or strong earnings momentum. In other words, a Value investor prefers current payments, while the Growth investor is willing to consider payments in the future. For a detailed explanation of the data and the methodology for their calculation, refer to www.mscibarra.com (MSCI-Barra, 2005).

16 The EU12 consists of Germany, France, Italy, Spain, Portugal, Greece, Netherlands, Belgium, Luxembourg, Ireland, Austria, Finland.

17 Since a specific inflation figure for EU-15 plus Switzerland was either not obtainable or does not exist in the sufficient length, EU-12 was considered as a plausible proxy.

18 While deflating is the standard procedure in the relevant literature, which is also the reason why it is used here, it is unclear whether it is necessary in the case of equity prices. On one hand prices are the ratio of two nominal values $\left(\frac{\text { nominalcashflow }}{1+\text { nominaldiscountrate }}\right)$, which itself should be in real terms, as the price deflator should cancel out. On the other hand, when assuming that all financial investments are essentially just a means to provide consumable funds, then in a nominal world the evaluation of such investments, i.e. the price, should also be nominal.

19 All indices are provided by MSCI-Barra as a price index as well as two different total return indices (gross return and net return). While the prior simply represents changes in the corresponding prices of the index' constituents, the total return indices reinvest dividend payouts. The gross return index takes into account all dividends payed by a company, while the net return index makes tax deductions and reinvests only the minimum dividend received by an investor. For this analysis the net dividends are being used. Furthermore, indices are available in US-dollar as well as local currency denomination. As prior studies showed that the results differ only slightly between US-dollar and local currency denomination, the study at hand uses US-dollar data, since it is available more consistently for a longer period of time. 
$D_{t}=$ dividend index

$P F_{t}=$ performance index

$P_{t}=$ price index

Using this information, values for $D_{t}$ can be obtained by rearranging equation (18):

$$
D_{t}=\left(\frac{P F_{t}}{P F_{t-1}} \cdot P_{t-1}\right)-P_{t}
$$

Unfortunately, while obtaining the dividend series, a structural break in the dividend data was revealed. At the beginning of 2001, MSCI-Barra changed its methodology. Up to December 2000 total return indices were only available in monthly frequency and dividends were incorporated in the index by reinvesting $\frac{1}{12}$ th of the annual dividend yield of the total index each month - essentially a smoothing of dividends took place. From January 2001, these monthly total return indices were changed to daily performance indices, which reinvest the distributed dividends when the corresponding share price is reported "ex-dividend", i.e. on the day when dividends are officially being payed out. A structural break in the data is the result, as can be seen in the case of the Standard index in figure 1. Clearly, the data after the change in the methodology reflects reality much closer, while prior to January 2001 it reflects a smoothed approximation.

Figure 1: Price and dividend series for the Standard index

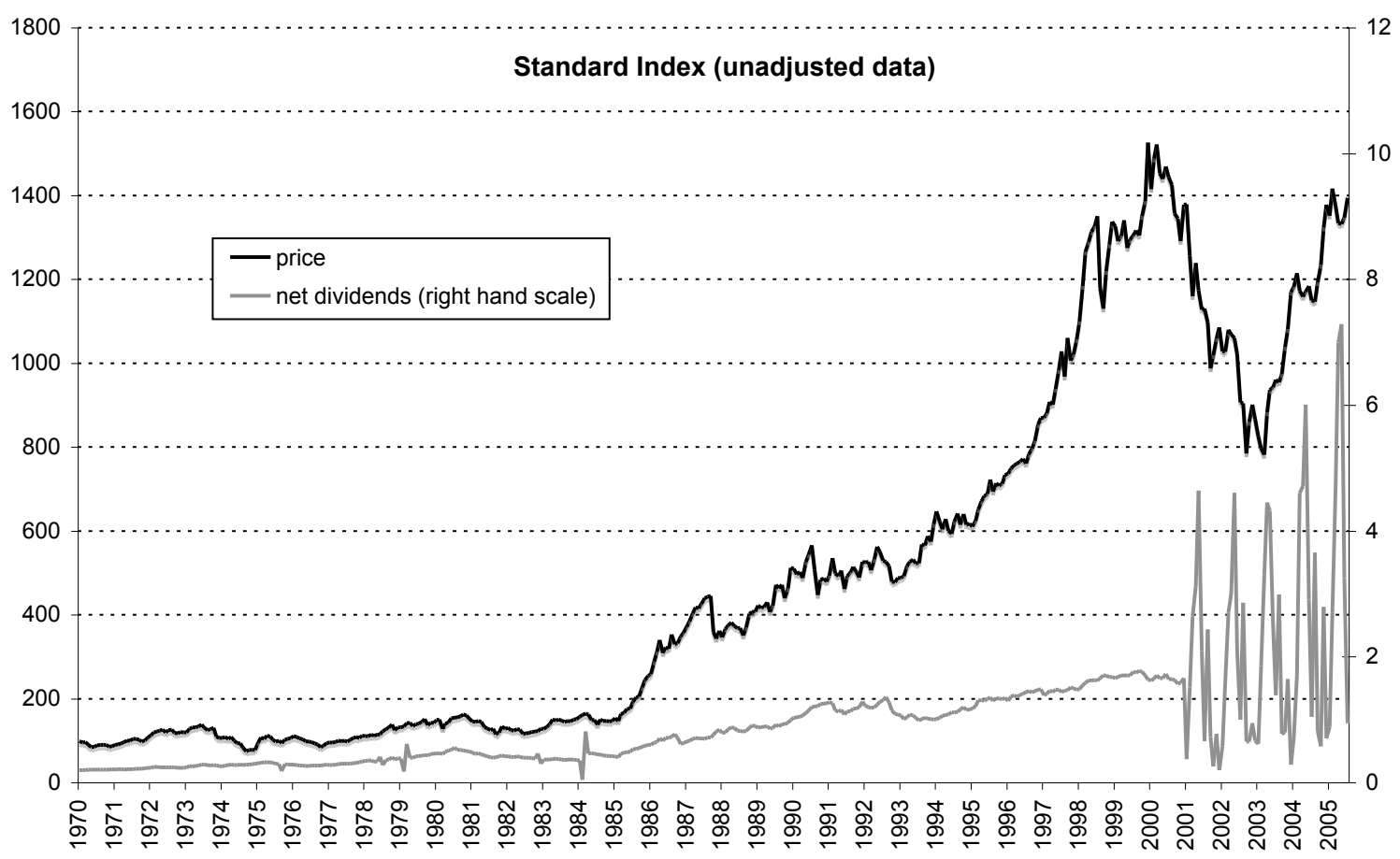

Source: MSCI-Barra; own calculations

Price $\left(P_{t}\right)$ and dividend $\left(D_{t}\right)$ series for the MSCI-Europe Standard Index. Series are denominated in US-Dollar and dividends are net of taxes, according to the methodology by MSCI-Barra. 
Upon closer inspection of the obtained dividend series, it can be seen that after 2001 they follow a relatively stable seasonal pattern. From a theoretical point of view, it is not implausible to assume that this seasonal pattern also was stable over the whole sample period. Companies pay dividends a short time after their annual shareholder meeting, which usually occurs a few months after the end of the company's financial year. Besides institutional changes such as particular legislature, for example, there are not many reason why a company should change the end of its financial year. In fact, such a change is potentially very costly, so a firm has an incentive to leave arrangements unchanged. The result is a stable pattern of dividend payments within an index. ${ }^{20}$ Using an ARIMA X-12 procedure, as implemented in Eviews $5,{ }^{21}$ it is possible to isolate these stable seasonal factors, which then can be applied to the data prior to the structural break in January 2001. This should approximate the dividend series, as it would have been without the smoothing by MSCI-Barra. ${ }^{22}$

Figure 2: Seasonally adjusted dividends for the Standard index

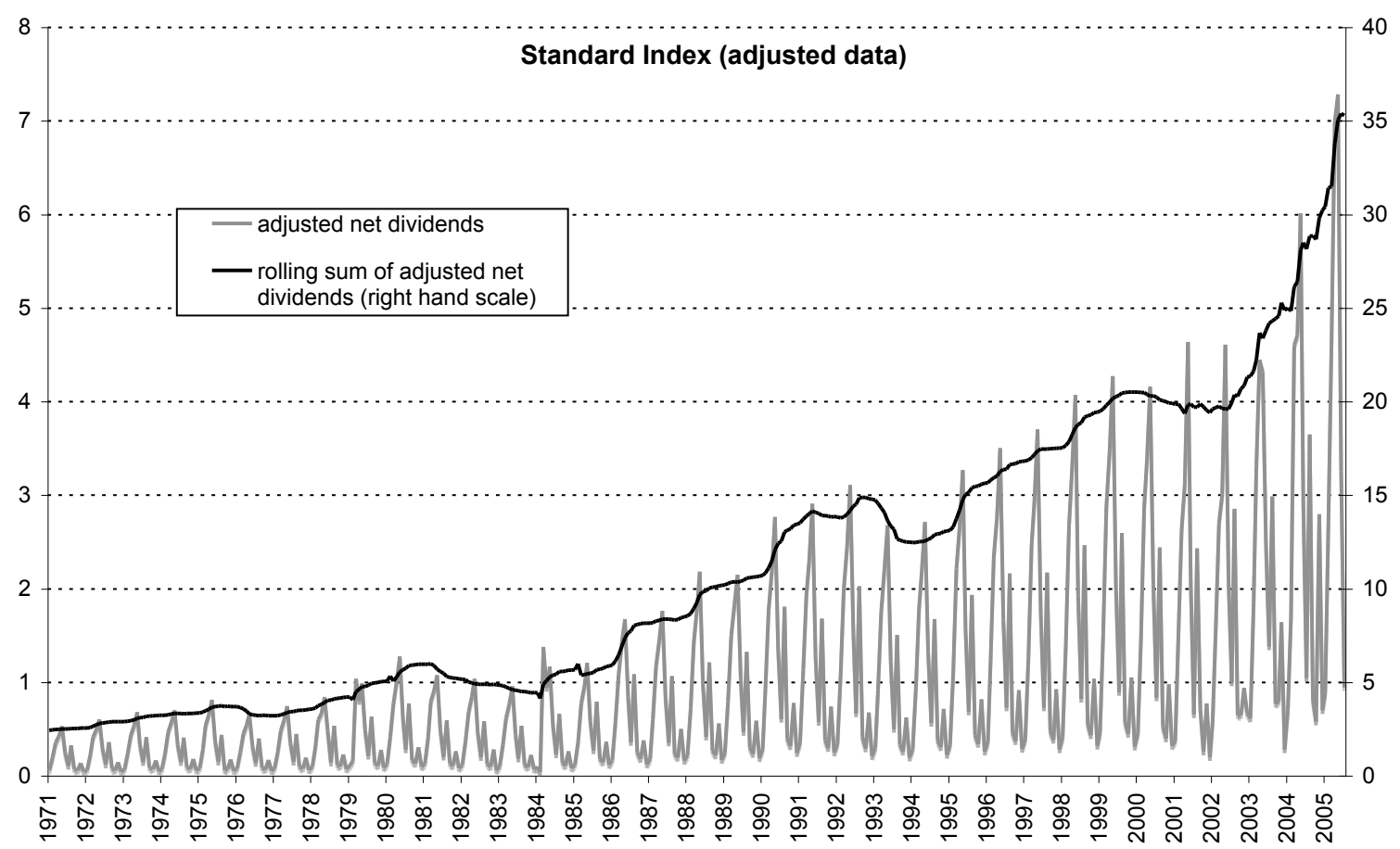

Source: MSCI-Barra; own calculations

Seasonally adjusted dividend series for the MSCI-Europe Standard Index. Seasonal factors were obtained from the original series after the year 2000 and were applied to the data prior to 2001 . The top line is a twelve-months rolling sum of the seasonally adjusted dividend series.

20 An alternative dividend series for the EU15, reaching back to the end of the 1980s by S\&P, also showed a stable seasonal pattern. Unfortunately, this series could not be used, since it would not have allowed for comparability with Berneburg (2006).

21 Bohley (2000, p. 278) considers the Census ARIMA procedure the standard approach for seasonal adjustments.

22 Berneburg (2006) showed that adjusting the data to the seasonal pattern did not fundamentally affect the results of a standard excess volatility tests. 
An additional characteristic of the data called for some further adjustments: On a monthly basis, there is a mismatch between prices and dividends. While the price index at any given time $t$ represents the prices of all constituents, not all companies will pay dividends in every $t$. In other words, in any given month, the above described GGM tries to match a small group of companies paying dividends with a price index covering all companies; clearly a mismatch. In order to overcome this problem, the obtained dividend series are transformed into monthly rolling sum of the past twelve dividend payments $\left(\sum_{i=0}^{11} D_{t-i}\right)$. It is this seasonally adjusted rolling sums data that is used in the calculations below. While these rolling sums on first sight do not seem to be any different than annual data, which would put the use of monthly data in question. But the nature of the rolling sum is that every new month contains an additional set of incremental information which annual data would not be able to pick up. Figure 2 depicts the seasonally adjusted data as well as the rolling sums using the Standard index as an example. 


\section{Results}

The following section will discuss the results of the above described approaches.

Tables 1 and 2 show the standard deviation ratios of $p_{t}$ and $p_{t}^{c}$ as well as $p_{t}$ and $p_{t}^{v}$ depending on the index type and the value for $\theta$, the relative importance of the permanent component in $g_{t}$ and $r_{t}^{v}{ }^{23}$ The first thing that becomes apparent is the fact that, irrespective of the type of index, no values are available for $\theta$ s up to 0.99 or 0.995 , i.e. the importance of the permanent component in the estimation procedure in $g_{t}$ and $r_{t}^{v}$ takes a high weighting. In these cases the requirement of the GGM, that $r_{t}>g_{t}$ is not fulfilled, as the volatility of $g_{t}$ increases dramatically as $\theta$ decreases. This confirms Barsky and DeLong's (1993) finding that the true value of $\theta$ should be very close to one. In fact, Barsky and DeLong point out that given the amount of data and the magnitude of the transitory shocks it is too difficult to precisely estimate whether $\theta$ is one or just very close to one. But their results using $\theta=1$ indicate excessively volatile prices, i.e. the estimation process does not seem to capture all sources of volatility. As $\theta=1$ implies that market participants completely disregard all transitory shocks, which would raise the volatility of fundamental prices, they conclude that $\theta$ is most likely close to but not equal to one.

This also explains the second notable result in tables 1 and 2; why the ratios, and their proximity to one, are very sensitive to the value of $\theta$. As it increases and approaches one, i.e. market participants pay little to no attention to transitory shocks, the volatilities of $p_{t}^{c}$ and $p_{t}^{v}$ decrease so that the respective standard deviation ratios rise from below one (i.e. conforming with the EMH: no excess volatility) to close to two (i.e. falsifying the EMH: prices are twice as volatile as a fundamental price based on dividend movements). This points to a disadvantage of Shiller's variance bound: It is not a statistical test. In other words, one is unable to judge whether the observed deviations from one are statistically significant. But Berneburg (2006) using identical data shows, based on a restriction tests in a VEC-framework, that similar values as observed here are indeed significantly different from one and are more likely to be close to two.

Thirdly, it seems that, similar as in Berneburg (2006), the mean discount factors (i.e. $\frac{1}{T+1} \sum_{t=0}^{T} \ln \frac{1+g_{t}}{r_{t}^{c}-g_{t}}$ or $\left.\frac{1}{T+1} \sum_{t=0}^{T} \ln \frac{1+g_{t}}{r_{t}^{v}-g_{t}}\right)$ for all indices are roughly equal, which would imply that the discount rates $\left(r_{t}\right)$ compensate for the different dividend growth rates of the equity styles. In other words, market participants in fact seem to treat all investment styles in an equal manner, since they presume that on a risk-adjusted basis all investment styles perform similarly. But when testing the discount factors of the different equity styles for equality by using a Diebold-Mariano Test (Diebold

23 While Barsky and DeLong (1993) find that $\theta$ should be close to one, there is no appropriate rule for setting/finding a true value. To overcome this problem, results were obtained for $\theta \mathrm{s}$ between zero and one taking steps of 0.005 . These results were then analyzed in terms of their plausibility. No results for $\theta$ s below 0.995 delivered possible values (tables 1 and 2). 
Table 1: Standard deviation ratios of $p_{t}$ and $p_{t}^{c}$ and discount factors

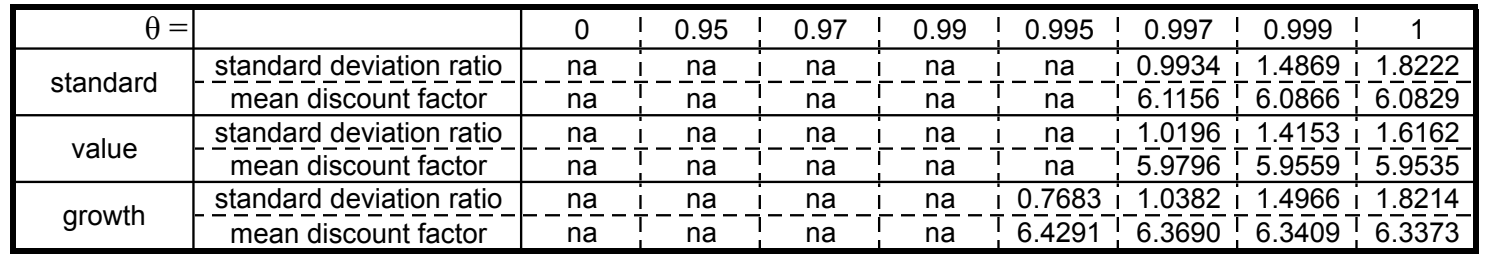

Source: own calculations

Ratios between the standard deviation of prices $p_{t}$ and the fundamental price calculated with a fixed discount rate $\left(p_{t}^{c}\right)$, which was estimated as the average of a perfectly fitting discount rate (equations (14) and (15)). The mean discount factor corresponds to the average of the discount factor in the Gordon Growth Model. The different values for $\theta$ determine importance of short-term transitory shocks in the estimation procedure. The closer the value is to one, the less important transitory shocks become. Values of $\theta$ smaller than 0.995 lead to a violation of the Gordon Growth Model and are hence implausible.

Table 2: Standard deviation ratios of $p_{t}$ and $p_{t}^{v}$ and discount factors

\begin{tabular}{|c|c|c|c|c|c|c|c|c|c|}
\hline$\theta=$ & & 0 & 0.95 & 0.97 & 0.99 & 0.995 & 0.997 & 0.999 & 1 \\
\hline \multirow[b]{2}{*}{ standard } & standard deviation ratio & na & na & na & na & 0.9298 & 1.5818 & 2.0438 & 1.8222 \\
\hline & mean discount factor & na & ña & nà & nà & $5 . \overline{9} \overline{9} \overline{9}$ & $5 . \overline{91} \overline{6} 5$ & $\overline{5} . \overline{9} 3 \overline{9} \overline{0}$ & $\overline{5} . \overline{9} \overline{6} \overline{6} \overline{5}$ \\
\hline \multirow{2}{*}{ value } & standard deviation ratio & na & na & na & na & $1.17 \underline{52}$ & 1.4314 & 1.6086 & 1.6162 \\
\hline & mean discount factor & na & nà & na & nà & $5.3 \overline{6} 32$ & $5 . \overline{3} 8 \overline{2} 3$ & $\overline{5} . \overline{4} 4 \overline{9} \overline{8}$ & $\overline{5} . \overline{5} \overline{1} \overline{1} \overline{1}$ \\
\hline \multirow{2}{*}{ growth } & standard deviation ratio & na & na & na & na & 0.9812 & 1.4526 & 1.8261 & 1.8082 \\
\hline & mean discount factor & na & nà & nà & na & $5.68 \overline{6} \overline{-}$ & $5 . \overline{6} \overline{5} \overline{3}$ & $\overline{5} \overline{\overline{7}} \overline{\overline{4}} \overline{6} \bar{\top}$ & $\overline{5} . \overline{8} \overline{51} \overline{6}$ \\
\hline
\end{tabular}

Source: own calculations

Ratios between the standard deviation of prices $\left(p_{t}\right)$ and the fundamental price calculated with a fixed discount rate $\left(p_{t}^{v}\right)$, which was estimated using equations (16) and (17). The mean discount factor corresponds to the average of the discount factor in the Gordon Growth Model. The different values for $\theta$ determine importance of short-term transitory shocks in the estimation procedure. The closer the value is to one, the less important transitory shocks become. Values of $\theta$ smaller than 0.995 lead to a violation of the Gordon Growth Model and are hence implausible.

and Mariano, 1995) with a Newey-West autocorrelation and heteroskedasticity robust estimator (Newey and West, 1987), a clear rejection of the null hypothesis of statistically equal time series is the result in all cases (table 3). Considering these results, the hypothesis of equal discount factors for all investment styles has to be viewed with caution and the investment styles in fact seem to perform differently.

It should be noted that the above results and their interpretations hold both for the case when $r_{t}$ is fixed at $\overline{r^{c}}$ as well as when $r_{t}$ takes the variable values of $r_{t}^{v}$. So, in other words, market participants do indeed treat the three investment styles differently. This indicates that on a risk-adjusted basis the investment styles show performance differences, which stands in contradiction to the EMH.

While up to this point $p_{t}^{c}$ and $p_{t}^{v}$ behaved very similar, the two sides of figure 3 which graphically compare $p_{t}$ with $p_{t}^{c}$ and $p_{t}^{v}$, respectively, point to some differences. It becomes apparent that just as in table 1 and 2 the behavior of the fundamental prices very much depends on the value of $\theta$, the weighting factor between the permanent and the transitory component in equations (13) and (16). As $\theta$ decreases (i.e. the importance of the transitory shock increases), the volatility of $p_{t}^{c}$ and $p_{t}^{v}$ increases. Both these fundamental prices approximate the movements in $p_{t}$ fairly well, it is $p_{t}^{c}$ that also matches the level of $p_{t}$ much closer, while $p_{t}^{v}$ tends to be too low. In other words, a constant discount rate $\left(\bar{r}^{c}\right)$ based on a calculation that perfectly solves the 
Table 3: Diebold-Mariano Test for equality of two series

\begin{tabular}{|c|c|c|c|c|c|}
\hline & Coefficient of constant & Std. Error & t-Statistic & $\mathrm{p}$-Value \\
\hline \multirow{4}{*}{ 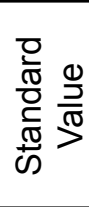 } & $\theta=0.995$ & $0.1041 i$ & $0.015261 i$ & $6.823108 i$ & 0.0000 \\
\hline & $\bar{\theta}=\overline{0} . \overline{9} \overline{9}$ & 0.0989 & 0.009059 & 10.918978 & 0.0000 \\
\hline & $\bar{\theta} \overline{=} \overline{0} . \overline{9} \overline{9} \overline{9}$ & $0 . \overline{1112}$ & $0.00 \overline{3079}$ & $\overline{36} . \overline{3495} \overline{1}$ & 0.0000 \\
\hline & $\bar{\theta}=\overline{1} .000$ & $0 . \overline{1} 294$ & $3.60 \mathrm{E}-18$ & $3.59 \mathrm{E}+16$ & 0.0000 \\
\hline \multirow{4}{*}{ 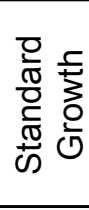 } & $\theta=0.995$ & -0.2842 & 0.0326109 & -8.714673 & 0.0000 \\
\hline & $\bar{\theta}=\overline{0} . \overline{9} \overline{9} \overline{-}$ & & 0.016331 & 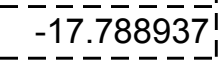 & 0.0000 \\
\hline & $\bar{\theta}=\overline{0} . \overline{9} 9$ & -0.2737 & 0.004793 & -57.104790 & 0.0000 \\
\hline & $\bar{\theta}=\overline{1} .000$ & $-0 . \overline{2544 !}$ & $5 . \overline{7} \overline{\mathrm{E}}-1 \overline{7}$ & $-4.41 \mathrm{E}+15$ & 0.0000 \\
\hline \multirow{4}{*}{ 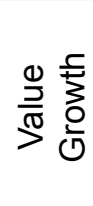 } & $\theta=0.995$ & $-0.3883 \mid$ & 0.0362706 & -10.706212 & 0.0000 \\
\hline & $\bar{\theta}=\overline{0} . \overline{9} \overline{9}$ & -0.3894 & 0.017301 & -22.508902 & 0.0000 \\
\hline & $\underline{\theta}=0.999$ & & 0.005368 & -71.709137 & 0.0000 \\
\hline & $\theta=1.000$ & -0.3838 & $1.44 \mathrm{E}-17$ & $-2.66 \mathrm{E}+16$ & 0.0000 \\
\hline
\end{tabular}

Source: own calculations

The null hypothesis $H_{0}$ of the Diebold-Mariano Test is whether the difference of two time series is equal to zero. Using the discount rates in the fixed discount rate case, the null hypothesis is being tested by regressing the difference of the discount factors of two indices on a constant. Should the coefficient of the constant be statistically significantly different from zero, $H_{0}$ will be rejected. The Newey-West autocorrelation and heteroskedasticity robust estimator of the constant is highly significant in all cases above.

GGM, matches market behavior better than a variable rate, which is calculated in the above manner. Figure 3 also indicates another point: Some level of mispricing seems to remain. This becomes especially clear as $\theta$ increases. While lower $\theta \mathrm{s}$ $(e . g . \theta=0.995)$ in some cases indicate implausibly high or low fundamental values as their volatility increases, it is the higher values of $\theta$ that provide sensible and more stable estimates of $p^{*}$. But they are characterized by systematic over- and underpricing in $p_{t}$. For example, the 1970s were a time of systematic underpricing, while the greatest part of the 1990s was an era of overpricing. In current times $\theta \mathrm{s}$ of 0.999 or 1 lead to fundamental values, which are being very nicely matched by prices. One possible explanation for the good fit of $\theta=1$ is that transitory shocks night not play an important role at the moment. At the same time, these estimates grossly fail to match market prices during the 1990s or, albeit to a lesser extent, the 1970s. A model, which seems to be able to explaining this situation is a world with two states: normal times and shock times. On the one hand, during the former, $\theta$ would be very close to one implying that market participants do not pay much attention to minor movements and changes, as they presume the long-term values for $g$ and $r$ to be stable. On the other hand, in times of a shock financial markets can not be certain whether current changes might in fact have a permanent component (e.g. the internet "revolution" of the 1990s). During such times, the value of $\theta$ adjusts downward and prices appear to drift away from a fundamental value, which was calculated using the $\theta$ value of the "normal" state.

Figure 4 allows for one last inspection of the data. For the three investment styles and depending on different $\theta \mathrm{s}$, it shows the values of $r_{t}^{c}$ in comparison to a de- 
Figure 3: Comparison of market prices and fundamental prices
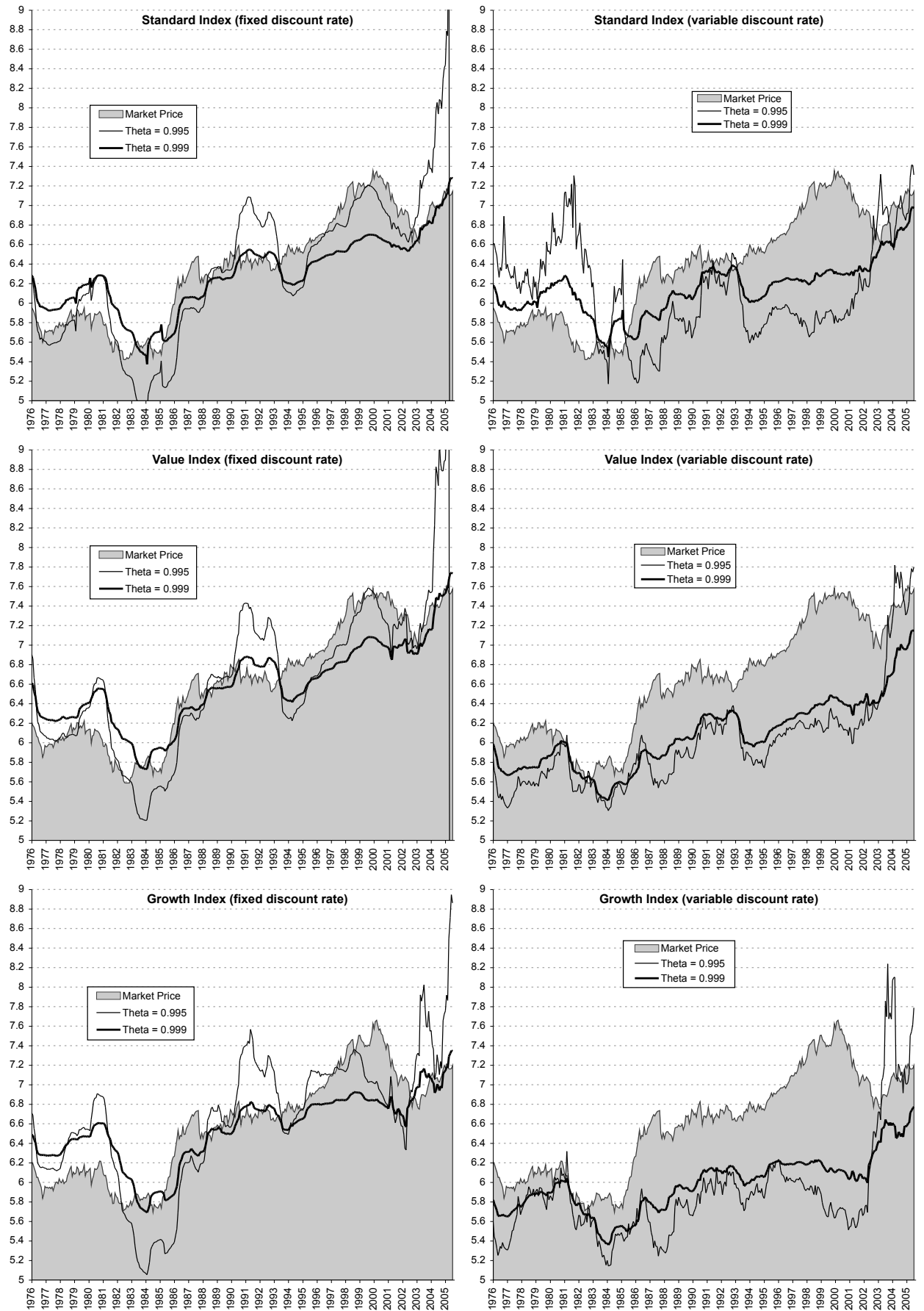

Source: own calculations

Graphical comparison of market prices $\left(p_{t}\right)$ and fundamental prices. The left column shows fundamental prices calculated based on a fixed discount rate $\left(p_{t}^{c}\right)$, which was estimated as the average of a perfectly fitting discount rate (equations (14) and (15)). The right column depicts fundamental prices calculated based on a fixed discount rate $\left(p_{t}^{v}\right)$, which was estimated using equations (16) and (17). The different values for $\theta$ determine importance of short-term transitory shocks in the estimation procedure. The closer the value is to one, the less important transitory shocks become. Values of $\theta$ smaller than 0.995 lead to a violation of the Gordon Growth Model and are hence implausible. 
Figure 4: Perfectly matching discount rate and 10 year German government bond
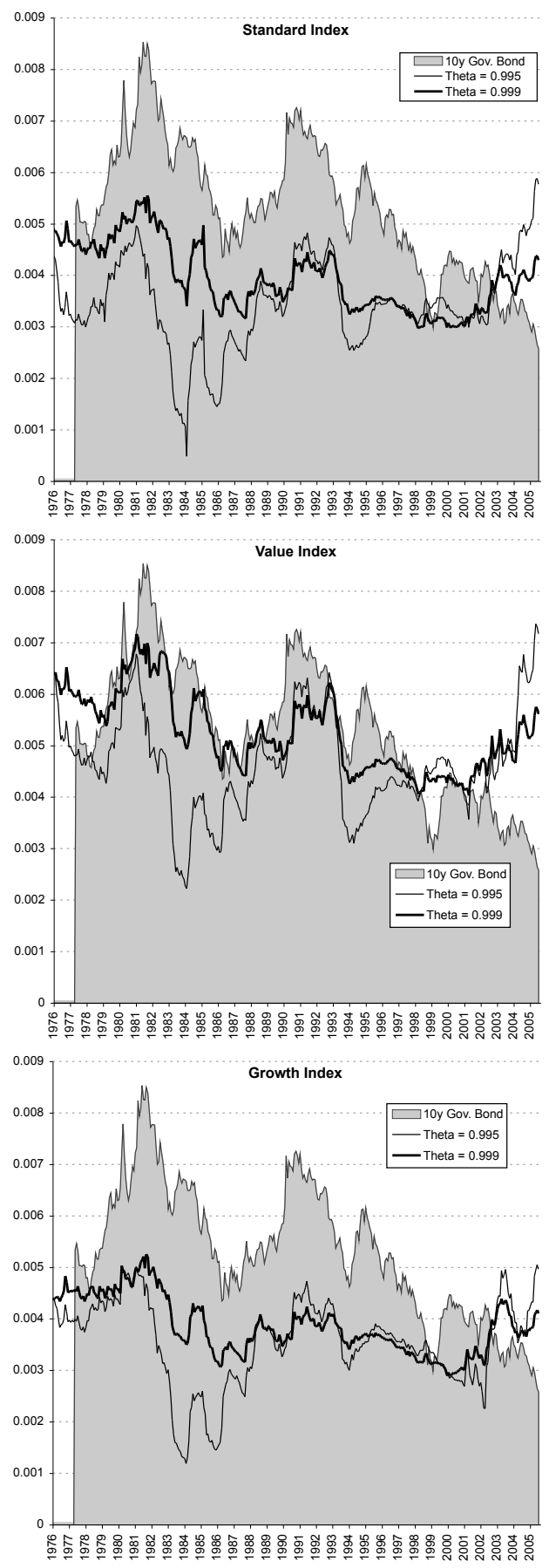

Source: own calculations

Graphical comparison of the discount rate $\left(r_{t}^{c}\right)$, which given equation (13) brings market prices and the fundamental prices perfectly in line with each other, and a ten year German government bond. The different values for $\theta$ determine importance of short-term transitory shocks in the estimation procedure. The closer the value is to one, the less important transitory shocks become. Values of $\theta$ smaller than 0.995 lead to a violation of the Gordon Growth Model and are hence implausible. 
flated $^{24}$ ten-year German government bond, which serves as a proxy for a European interest rate. The series should be closely matched in terms of their movements, as the government bond can be considered a substitute of some degree for an investment in European equities. ${ }^{25}$ Of course, this approximation is not very accurate, as most areas in Europe had for a large part of the time higher real interest rates than Germany, but general movements should have been the same across Europe. Furthermore, especially towards the end of the data, interest rates across Europe have converged, so that the degree of representativeness of the proxy should increase towards the end of the data. The comparison of $r_{t}^{c}$ and the German government bond allows for two conclusions. Firstly, most of the time their movements are very similar and in the case of the Value index, even the level is very closely matched. Also, the general tendency to decline over time can be found in the values for $r_{t}^{c}$. Secondly, as good as the series seem to match up until the late 1990s, the close relationship breaks down sometime between 1998 and 2002, after which the government bond and the different $r_{t}^{c} \mathrm{~s}$ move in opposite direction. The reason for this behavior is not entirely clear. But it reflects a situation that can also be seen in other areas of the financial market and which the former chairman of the Federal Reserve Open Market Committee (FOMC) of the United States, Alan Greenspan, called a "conundrum". During the most recent years, in a time of rising corporate profits, strong economic growth and rising short-term interest rates, longer-term interest rates (measured by ten-year government bonds) were declining. In other words, the reason for the deviation between the benchmark German Government Bond and the calculated discount rate $\left(r_{t}^{c}\right)$ might simply be due to unusual behavior in the bond yield rather than the discount rate. One possible explanation is over-saving (the so-called savings-glut) in East Asia, which provides strong demand for government bonds and hence pushing down their yield. While this is clearly only a partial explanation, the reasons for this "conundrum" are currently a hot topic in macroeconomics for which the discussion is still very much ongoing and too extensive to be discussed at this point.

24 For deflation the same implicit deflator from the OECD was used as in the cases above.

25 It should be pointed out that clearly government bonds and equity investments are only very imperfect substitutes. Their respective risks are highly different. But while this imperfection would surely lead to different yield levels, as to compensate for their levels of risk, their overall movements should be comparable. A comparison in terms of general behavior rather than total size seems plausible. 


\section{Conclusion}

One can conclude several things from the above results.

Firstly, Shiller's assumptions that the growth rates of dividends, the discount rate and the resulting discount factor are constant, a-priori reduced volatility in his estimation of a fundamental price $p^{*}$. As $\theta$ decreases, i.e. the importance of transitory shock increases, the volatility of the estimated $p^{*}$ increased strongly. But relaxing these assumptions does not eliminate excess volatility completely. In fact, the most plausible estimates of $p^{*}$ (high $\theta: \theta=0.999$ or 1 as well as a fixed rate of discount: $\left.\overline{r^{c}}\right)$ with variance ratios well above one and long stretches of mispricing, clearly indicate that some level of excess volatility remains. The results are very similar to the ones obtained from an earlier study by Berneburg (2006), where the long-term coefficient of dividends in terms of prices was in the vicinity of two.

Secondly, contrary to Berneburg (2006), the discount factors of the three investment styles at hand, while being close to each other, where shown to be statistically different from each other, pointing to some degree of inefficiency.

Finally and thirdly, although the used proxy for a European interest rate is not without flaws, it was found that the implicit discount rate $\left(r_{t}^{c}\right)$, which perfectly matches dividends to prices given an estimate of $g_{t}$, in most of the cases, behaves very similar to this proxy, as it should under efficiency. Only in the past three to eight years, this relationship has broken down, the reason for which is unsure. One possible explanation could be that the behavior of long-term interest rates might have changed in the wake of a more and more globalizing world economy.

Overall, it needs to be said that some degree of inefficiency can hence not be rejected. In fact, as figure 3 indicates, there seems to be some form of systematic overand underpricing (i.e. mean reversion) in the short-term. In other words, Shiller's assumptions do not seem to be the only reasons for his findings of excess volatility. In fact, it seems that the "small" degree of inefficiency that is needed to provide an incentive to collect information, as hypothesized by Kyle (1985), indeed is reflected empirically in the data. Besides theoretical reasons for the found mispricing, one can also mention some empirical and methodological arguments. Ackert and Smith (1993) point out that in many cases dividends are not the only relevant cash flows (e.g. gains from mergers and acquisitions etc.), so that this omission might in fact make the response of prices to pure dividend changes seem excessive. This is especially the case for newer companies which have not started to pay dividends. Growth share would fall into this group. A further characteristic of new, and hence of many Growth shares in the 1990s, for example, was that investors could not rely on past information about their dividend growth rate or the appropriate discount rate. In other words, they had to form an opinion heavily based on current events and shocks. In fact, it could quite possibly be that due to the lack of historic data, they reacted as if they placed a high weight on transitory shocks for their evaluation. But as more and more data became available, the weighting factor $(\theta)$ adjusted to 
more "normal" levels. An additional explanation would be a world with two different states. In a "normal" state, $\theta$ is quite high and very close to one. In times when many major structural changes are under way in the economy, e.g. the introduction of large scale productivity enhancing equipment in the 1990s, a regime change takes place towards lower levels of $\theta$. While the former is a bit more focused on the 1990s, the latter model of time-varying $\theta$ s would additionally be able to explain the slight mispricings during the 1970s, when due to the two oil price shocks economic circumstances were largely uncertain. So overall, while some possible explanations for the found level of inefficiencies exist, based on the above results, one cannot assume a fully efficient market; some degree of systematic mispricing seems to be in the European equity market. 


\section{References}

Ackert, L. F. and Smith, B. F. (1993). Stock price volatility, ordinary dividends, and other cash flows to shareholders, Journal of Finance 48(4): 1147 - 1160.

Barsky, R. B. and DeLong, J. B. (1993). Why does the stock market fluctuate?, Quarterly Journal of Economics 108(2): 291 - 311.

Berneburg, M. (2004). Are European equity style indices mean reverting? Testing the validity of the weak form Efficient Market Hypothesis, IWH Discussion Papers 193, Halle Institute for Economic Research (IWH).

Berneburg, M. (2006). Excess volatility in European equity style indices - New evidence, IWH Discussion Papers 16, Halle Institute for Economic Research (IWH).

Bohley, P. (2000). Statistik, Oldenbourg Wissenschaftsverlag GmbH, München.

Campbell, J. Y. (1991). A variance decomposition for stock returns, Economic Journal 101: 157 - 179.

Chow, K. V., Pan, M.-S. and Sakano, R. (1996). On the long-term or short-term dependence in stock prices: Evidence from international stock markets, Review of Quantitative Finance and Accounting 6: 181 - 194.

Cochrane, J. H. (1992). Explaining the variance of price-dividend-ratios, Review of Financial Studies 5: $243-280$.

Coggin, T. D. (1998). Long-term memory in equity style indexes, The Journal of Portfolio Management pp. 37 - 46.

Coggin, T. D., Fabozzi, F. J. and Arnott, R. D. (1997). The Handbook of Equity Style Management, 2nd edn, McGraw-Hill, NewYork.

Cuthbertson, K. and Hyde, S. (2002). Excess volatility and efficiency in french and german markets, Economic Modelling 19: 399 - 418.

Diebold, F. X. and Mariano, R. S. (1995). Comparing predictive accuracy, Journal of Business and Economic Statistics 13: 253 - 263.

Fama, E. F. (1965). The behavior of stock market prices, Journal of Business 38: 34 -105 .

Gillies, C. and LeRoy, S. F. (1991). Econometric aspects of the variance-bounds tests: A survey, Review of Financial Studies 4(4): 753 - 791.

Gordon, M. (1962). The Investment, Financing and Valuation of the Corporation, Irwin, Homewood, IL. 
Hardouvelis, G. A., Malliaropulos, D. and Priestley, R. (2006). EMU and european stock market integration, The Journal of Business 79: 365 - 392.

Heaney, R. (2004). Excess volatility? the australian stock market from 1883 - 1999, Managerial Finance 30(1): 76 - 94.

Kleidon, A. W. (1986a). Bias in small sample tests of stock price rationality, Journal of Business 59(2): 237 -261.

Kleidon, A. W. (1986b). Variance bounds tests and stock price valuation models, Journal of Political Economy 94(5): 953 - 1001.

Kleidon, A. W. (1988). Bubbles, fads and stock price volatility tests: A partial evaluation: Discussion, Journal of Finance 43(3): 656 - 660.

Kyle, A. S. (1985). Continuous auctions and insider trading, Econometrica 53: 1315 -1336 .

Levy, H. and Sarnat, M. (1970). International diversification of investment portfolios, American Economic Review 60-4: 668 - 75.

Lo, A. W. (1991). Long-term memory in stock market prices, Econometrica 59(5): $1279-1313$.

MSCI-Barra (2005). Standard indices - europe. www.mscibarra.com.

Muth, J. (1960). Optimal properties of exponentially weighted forecasts, Journal of the American Statistical Association LV: 299 - 306.

Newey, W. K. and West, K. D. (1987). A simple, positive semi-definite, heteroskedasticity and autocorrelation consistent covariance matrix, Econometrica 55(3): $703-708$.

OECD (2005). Main economic indicators. October Edition.

Shiller, R. J. (1981). Do stock prices move too much to be justified by subsequent changes in dividends?, American Economic Review 71(3): 421 - 436.

Shiller, R. J. (2003). From efficient markets theory to behavioral finance, Journal of Economic Perspectives 17(1): 83 - 104. 